\title{
EU, ESTUDANTE DE ENFERMAGEM E ENFERMEIRA: UMA NARRATIVA AUTOBIOGRÁFICA SOBRE FORMAÇÃO, PRÁTICA PROFISSIONAL E DOCÊNCIA NA PERSPECTIVA FREIRIANA
}

\author{
BIANCA JOANA MATTIA \\ Maria Elisabeth KLEBA \\ IVO DICKMANN \\ Universidade Comunitária da Região de Chapecó \\ (UNOCHAPECÓ), Chapecó, Santa Catarina, Brasil
}

\begin{abstract}
Resumo: O presente artigo busca, através do método da narrativa autobiográfica, descrever como as escolhas feitas ao longo da minha trajetória pessoal e profissional têm influência na construção do ser enfermeira docente. A formação no Curso de Enfermagem da Unochapecó foi baseada nos eixos do Pró-Saúde, que é ancorado nos pressupostos do pensamento de Paulo Freire, utilizando principalmente questões relativas à problematização e ao desenvolvimento da autonomia dos sujeitos no processo ensino-aprendizagem como referências teórico-metodológicas. A experiência da formação, baseada na práxis pedagógica freiriana, teve influências diretas nas escolhas, atitudes e caminhos percorridos na prática profissional e no meio acadêmico, gerando oportunidades de aprendizado e comprometimento, na transformação do mundo e das pessoas que convivem comigo, como resultado desse processo formativo.
\end{abstract}

PALAVRAS-CHAVE: Narrativa autobiográfica. Formação em Enfermagem. Prática Profissional. Docência. 
INTRODUÇÃO

"Ninguém começa a ser professor numa certa terça-feira às quatro horas da tarde. Ninguém nasce professor ou marcado para ser professor. $A$ gente se forma como educador permanentemente na prática e na reflexão sobre a prática" (FREIRE, 2006 p. 58). Começo a redigir minhas palavras com esse pensamento de Paulo Freire, sintetizando a presente narrativa autobiográfica. Permito-me, com essa narrativa, descrever e refletir como as escolhas, feitas ao longo de minha trajetória pessoal, especialmente acadêmica e profissional, tiveram influência na construção do ser enfermeira docente. Ressalto que a escrevo em um momento importante de minha trajetória acadêmica, em que estou concluindo o Mestrado em Ciências da Saúde na Universidade Comunitária da Região de Chapecó - Unochapecó. A narrativa possibilita o exercício de reflexão da construção de minha identidade profissional, considerando, como dizia Freire (2015), que somos seres inconclusos e, assim, aprendizes.

A narrativa autobiográfica permite aos indivíduos dar forma a suas experiências e, por meio da reflexividade, conferir sentido ao que antes não tinha. Permite-Ihes conhecer "como constroem a consciência histórica de si e de suas aprendizagens nos territórios que habitam e são por eles habitados, mediante processos de biografização." (PASSEGGI; SOUZA; VICENTINI, 2011, p. 371).

A narrativa é uma forma suscetível de manifestar a vida. Por meio dela é possível fazer uma avaliação de si mesmo, seja como autoavaliação, seja como avaliação por outrem. "O que sou não me é diretamente acessível, eu só me descubro numa história, refletindo sobre meus atos depois que eles acontecem. Eu sou quem me tornei, o que a vida fez de mim ou o que eu fiz de minha vida." (FABRE, 2011, p. 355). Por outro lado, essa metodologia possibilita que o pesquisador e o sujeito autor da narrativa se tornem parceiros "na produção de significados e na reflexão sobre a experiência narrada", à medida que o narrador deixa de ser um "mero informante, para, também, assumir o papel de pesquisador de sua própria ação." (CUNHA; CHAIGAR apud GASTAL; AVANZI, 2015, p. 153).

Na presente narrativa, uma das dimensões do contexto relevantes para situar a reflexão é o processo de reorientação do modelo assistencial atualmente em curso no Brasil. As mudanças no Sistema de Saúde, a partir da Constituição Federal de 1988, e consequentemente, da criação do Sistema Único de Saúde (SUS), em 1990, requerem novas formas de gerir e de cuidar, fazendo emergir a necessidade de transformações na formação 
profissional em saúde. Buscando orientar o modelo de ensino em saúde, com base nos princípios e diretrizes do SUS, o Ministério da Saúde criou, em 2005, em parceria com o Ministério da Educação, o Programa Nacional de Reorientação da Formação Profissional em Saúde (Pró-Saúde), cuja proposta é ancorada em pressupostos freirianos, principalmente na problematização, na perspectiva da educação permanente, no processo de conscientização dos sujeitos, na dialogicidade e no papel de sujeito que o estudante assume em seu processo de aprendizagem, em interação com o professor, ambos mediados pela realidade.

A Universidade Comunitária da Região de Chapecó - Unochapecó - aprovou nesse mesmo ano de 2005 seu primeiro projeto no Edital do PróSaúde para o Curso de Enfermagem. Em 2008, um novo projeto foi aprovado, junto ao segundo Edital do Pró-Saúde, desta vez como Proposta Integrada, que reuniu, em 34 subprojetos, os dez cursos da saúde ofertados na época pela instituição, incluindo ainda o Curso de Jornalismo.

No ano de 2009, iniciam também na Unochapecó atividades vinculadas ao Programa de Educação pelo Trabalho para a Saúde (PETSaúde), como estratégia complementar do Pró-Saúde para a integração ensino-serviço-comunidade. Como princípio central para a organização de grupos tutoriais, os professores envolvidos na coordenação dos projetos adotaram a interdisciplinaridade e o trabalho em equipe multiprofissional, critério que determinou a seleção dos docentes, estudantes e profissionais para sua composição.

A motivação em realizar esta narrativa está relacionada à minha vivência como acadêmica do Curso de Enfermagem da Unochapecó, integrante da turma que iniciou no ano de 2007, primeira turma a ingressar no Curso com a proposta curricular articulada ao Pró-Saúde, com egressos no primeiro semestre de 2011. Nesse período, tive a oportunidade de atuar como estudante bolsista do PET-Saúde da Família. Essas experiências contribuíram significativamente para minha atuação profissional quando, em 2011, iniciei como enfermeira da Estratégia Saúde da Família (ESF) em um município de pequeno porte na região oeste do estado de Santa Catarina. Na continuidade, contribuiu em minha construção docente o fato de que, em 2014, ingressei no mestrado em Ciências da Saúde, vinculado à linha de pesquisa Formação e Trabalho em Saúde.

A construção da narrativa autobiográfica tem sua relevância na compreensão de que o saber da experiência é sempre individual, subjetivo, relativo e pessoal, sendo que duas pessoas, ainda que compartilhem um mesmo acontecimento, não fazem a mesma experiência e ninguém pode 
aprender pela experiência de outro (LARROSA BONDÍA, 2002). Nesse sentido o saber da experiência:

[...] requer parar para pensar, parar para olhar, parar para escutar, pensar mais devagar, olhar mais devagar, e escutar mais devagar; parar para sentir, sentir mais devagar, demorar-se nos detalhes, suspender a opinião, suspender o juízo, suspender a vontade, suspender o automatismo da ação, cultivar a atenção e a delicadeza, abrir os olhos e os ouvidos, falar sobre o que nos acontece, aprender a lentidão, escutar aos outros, cultivar a arte do encontro, calar muito, ter paciência e dar-se tempo e espaço. (LARROSA BONDÍA, 2002, p. 24).

Por outro lado, a construção da narrativa autobiográfica requer selecionar escritas de si que tenham sentido, numa perspectiva aberta à reflexividade. Para Fabre (2011, p. 357), a narrativa deve superar a descrição de si e de suas experiências como registro de certezas; "é preciso pensar um sujeito em busca de si, nunca completamente seguro do que ele é e envolvido na desconstrução de falsos selfs." Nessa perspectiva, apesar de assumir a subjetividade como objeto de estudo e categoria analítica, "visto que se trata de conhecer e compreender os significados que cada um atribui ou atribuiu em cada período da sua existência aos acontecimentos e situações que viveu", a narrativa autobiográfica requer situar a experiência no contexto histórico no qual ela ocorreu, desvelando ações e relações decisivas em sua construção. (JOSSO apud GASTAL; AVANZI, 2015, p. 153).

Nesse sentido, narrar minha trajetória de construção do ser enfermeira docente implica reconstituir e estabelecer relações entre experiências de vida, o processo de formação e a atuação docente, para o que Josso (apud PASSEGGl; SOUZA; VICENTINI, 2011) propõe como base os conceitos de experiências formadoras e de recordações referências. Como recordações referências compreendemos situações que "constituem um marco na trajetória e servem de parâmetro para o que segue na vida. [Já] as experiências formadoras são definidas [...] como aquelas que implicam 'uma articulação conscientemente elaborada entre atividade, sensibilidade, afetividade e ideação."' (JOSSO apud PASSEGGI; SOUZA; VICENTINI, 2011, p. 373-4).

O objetivo desta narrativa é descrever experiências referências em minha trajetória pessoal, como estudante de graduação do curso de Enfermagem da Unochapecó e como profissional da saúde, refletindo sobre que aspectos elas tiveram repercussão na formação do meu ser profissional de saúde docente. 
O CURSO DE GRADUAÇÃO EM ENFERMAGEM E OS PRESSUPOSTOS FREIRIANOS

A Unochapecó implantou o curso de Enfermagem no ano 2000, sendo homologado pelo Decreto 1692 de 26 de abril de 2004, e recredenciado pela Resolução 012, em 30 de março de 2014. A partir de 2002, os docentes iniciaram um processo de revisão do Projeto Pedagógico do Curso (PPC), envolvendo discentes, profissionais do serviço, gestores e comunidade, a fim de atender desafios inerentes às transformações da educação na saúde no Brasil e às demandas provocadas pela complexidade dos conceitos de saúde e da legislação vigente. Essas demandas são reforçadas com a aprovação das Diretrizes Curriculares Nacionais (DCN) para o ensino de graduação em Enfermagem, estabelecidas pela Resolução № 3 de 7 de novembro de 2001, as quais passaram a regulamentar o ensino de enfermagem em todo país, trazendo orientações para organização, desenvolvimento e avaliação dos projetos pedagógicos dos cursos de Graduação em Enfermagem. De acordo com as DCN, os profissionais dessa área devem ser preparados para atuar no Sistema Único de Saúde (BRASIL, 2001).

A partir de 2005, com o lançamento dos editais do Pró-Saúde pelos Ministérios da Saúde e da Educação, o curso de Enfermagem da Unochapecó teve a oportunidade de participar do Programa, intensificando a reformulação do PPC, já em andamento. O que se pretende com o Programa é que a formação transcenda o modelo clínico-individual e curativo para um modelo de saúde que leve em consideração as reais necessidades da população e os determinantes e condicionantes do processo saúde doença; e que os cenários de formação em saúde sejam diversificados. E, por fim, que o modelo pedagógico utilizado na formação dos profissionais de saúde seja baseado em metodologias ativas de ensino-aprendizagem em que os estudantes assumam papel de sujeitos em seu processo formativo (BRASIL, 2007).

Em relação à estrutura curricular, o curso de Graduação em Enfermagem prevê agrupar áreas de conhecimentos, formando núcleos de conhecimento específico. Três dimensões formam o eixo curricular articulador dos núcleos e fases do curso, sendo eles: promoção da saúde, cuidado holístico, e gestão e gerência. Para a integralização curricular, o estudante deverá participar das atividades previstas no PPC, tais como: atividades teóricas, teórico-práticas, estágio supervisionado e atividades curriculares complementares. Além disso, o curso, com base na importância da articulação entre ensino, pesquisa e extensão, incentiva a participação dos docentes e estudantes em atividades de iniciação científica, em projetos de pesquisa, grupos de extensão, seminários, encontros científicos, palestras, dentre outras. 
Nesse processo devem estar envolvidos professores, estudantes, profissionais da saúde e comunidade em geral.

Em nossa percepção, a formação no curso de Enfermagem da Unochapecó contempla os três eixos do Pró-Saúde, sendo: eixo A: orientação teórica; eixo B: cenários de prática; eixo C: orientação pedagógica. Podemos observar que os três eixos que estruturam a proposta do Pró-Saúde vão ao encontro do modelo de educação proposto por Paulo Freire.

Em seu primeiro eixo, orientação teórica, o Pró-Saúde propõe que a formação dos profissionais de saúde leve em conta as necessidades epidemiológicas, de tal forma que os prepare a realizar a avaliação crítica da saúde da população, considerando o contexto da realidade em que ela se encontra, para desenvolver ações que contribuam para a transformação dessa realidade. Paulo Freire, em sua proposta de educação, chama esse processo de conscientização, que consiste na capacidade dos sujeitos de imersão na realidade. Após a imersão, Freire (1980) propõe que os sujeitos se afastem do objeto. $\mathrm{O}$ afastamento consiste na tomada de consciência. Posterior à conscientização, espera-se que os sujeitos proponham respostas criativas de enfrentamento, capazes de transformar a realidade.

O segundo eixo, cenários de prática, consiste na interação ativa do educando com a população e com os profissionais de saúde em todo o processo de formação. Essa interação deve ocorrer em todos os espaços da comunidade, com os diversos sujeitos envolvidos na realidade. Para Paulo Freire (2015), a educação acontece entre os homens porque eles são incompletos. Ao buscar se completar, relacionam-se por meio do diálogo e, mediatizados pelo mundo, tornam-se mais humanos. O conhecimento é, dessa forma, produto das relações humanas.

O terceiro eixo, orientação pedagógica, propõe metodologias de ensino-aprendizagem com base na problematização, que levem o estudante a ser sujeito e o professor facilitador no processo de ensino-aprendizagem. O programa traz um modelo pedagógico baseado no aprender fazendo, assumindo que o conhecimento se constrói por esse meio. Dessa forma, esse é o eixo em que mais visualizamos a teoria de educação proposta por Freire, na medida em que propõe a problematização como estratégia metodológica do processo educativo, fomentando a criticidade dos estudantes, estimulando sua criatividade, a reflexão e a ação sobre a realidade. Em relação ao estudante ser sujeito, o mesmo autor diz que a vocação ontológica do ser humano é a de ser sujeito, e não objeto, e refletir sobre a realidade na qual está inserido (FREIRE, 2015). 
Nesse contexto, o curso de Enfermagem da Unochapecó, sendo instigado pelos programas de reorientação da formação, dos Ministérios da Saúde e da Educação, assume seu compromisso político com a educação. O curso se propõe a reorientar o modelo de formação dos profissionais de enfermagem, tendo em vista a consolidação do SUS como direito garantido por meio de diversas lutas de movimentos sociais.

Da mesma forma, Freire também afirma que a educação é um ato político. Ele nos diz que a educação apresenta uma dimensão política e gnosiológica. A dimensão política é a leitura de mundo e a dimensão gnosiológica é a leitura da palavra, dos conceitos, das categorias, das teorias, das disciplinas, sendo que a dimensão política fornece os fundamentos para a dimensão gnosiológica (ROMÃO, 2016).

Freire defende a educação emancipatória como leitura de mundo. Afirma que a educação deve ser um ato político e não de transferência de conhecimento, uma ciência aberta às demandas populares com base na participação da comunidade. Essa educação envolve conscientização de todos os sujeitos do processo no desvelamento do mundo, por meio da problematização da realidade e da dialogicidade. Isso implica o desenvolvimento crítico da leitura de mundo e um trabalho político de conscientização (BAQUERO, 2016).

\section{NARRATIVA AUTOBIOGRÁFICA: RECONHECENDO EXPERIÊNCIAS REFERÊNCIAS NA FORMAÇÃO DO SER PROFISSIONAL DE SAÚDE DOCENTE}

Desde a infância nutro a vontade de ser professora, contrariando o desejo de minha mãe. Venho de uma família materna que possui a docência em suas raízes, em que meus avós eram professores e dedicaram suas vidas à profissão docente. Dentre os sete filhos, cinco são professores. Isso sempre alimentou uma grande admiração em mim pela profissão e a vontade de segui-la. Queria ser professora, pois alimentava a imaginação de seguir os passos da família e de me aproximar ao compromisso social e político que a docência exige.

Frequentei o ensino fundamental em escola pública, e durante a infância, adolescência e juventude tive a oportunidade de participar de diversos movimentos e grupos sociais, como grupo de escoteiros, pastoral da juventude, grêmio estudantil, dentre outros. Nesses grupos exerci papéis de liderança que me eram atribuídos, na maioria das vezes, pela minha habilidade e maturidade em lidar com problemas e situações conflitantes e desafiadoras e, ainda, pela capacidade de comunicação. Considero que 
essas oportunidades de participação me possibilitaram desenvolver algumas habilidades, dentre elas a liderança, porém, considero que essa aprendizagem ficou incompleta, necessitando ser lapidada ao longo de minha trajetória.

A respeito disso, Freire (2015) nos diz que é agindo no mundo que os sujeitos constroem o conhecimento, ou seja, o conhecimento nasce da ação-reflexão-ação. Um sujeito não aprende sozinho, faz isso em um contexto social, nas práticas cotidianas, indicando e contribuindo para que as mudanças sociais aconteçam, e esses sujeitos influenciam e são influenciados pelo contexto e pelas relações que desenvolvem. Portanto, a aprendizagem é fundamentalmente um processo social. A aprendizagem é o estar no mundo, interagir e participar do mundo social. O conhecimento está presente nas práticas cotidianas, na cultura de um grupo, de uma comunidade ou organização (SCHOMMER; BOULLOSA, 2010).

Já no ensino médio, frequentei uma escola cenecista, que funcionava em período noturno e assim me possibilitava trabalhar durante o dia. Foi nesse período que tive meu primeiro emprego, como secretária em uma pequena empresa, que me permitiu vivenciar o mundo do trabalho e desenvolver responsabilidades com horários.

Estudar à noite me possibilitou outras experiências e reflexões, como compartilhar momentos com pessoas que, como eu, haviam trabalhado o dia todo. Cansados, enfrentávamos aulas, com conteúdos exaustivos de preparo para o pré-vestibular, com docentes que, na maioria das vezes, utilizavam métodos tradicionais de ensino-aprendizagem, apesar de, em alguns momentos, buscarem introduzir métodos mais participativos. Porém, havia uma quantidade de conteúdos a serem ministrados pelos professores e uma carga horária reduzida no ensino noturno que dificultavam as iniciativas pontuais dos docentes.

Durante o ensino médio, precisei fazer uma das principais escolhas que uma adolescente aos dezesseis anos precisa realizar: a profissão. Dentre muitas conversas com a família, todas refutadas, na tentativa de convencê-los a me deixar ser professora, minha mãe sugeriu que eu fizesse enfermagem. Movida pelo sentimento de apoio e segurança na proposta de minha mãe, decidi que faria enfermagem. Também escolhi essa profissão por exigir, como a docência, dedicação, cuidado, diálogo, proximidade com o ser humano e, de alguma forma, possibilitar-me contribuir positivamente e diretamente na vida das pessoas. E, principalmente, pela possibilidade de transformação da realidade.

Paulo Freire chama esse processo de humanização, salientando que a vocação para a humanização é da natureza humana. Isso se expressa na 
busca pelo ser mais, pelo que o ser humano está em permanente busca, como parte do conhecimento de si e do mundo. A luta pela humanização se funda antropologicamente e eticamente no processo de construção do ser inconcluso (ZITKOSKI, 2016; ROMÃO et al, 2006).

Ao final do ano de 2006, realizo vestibular e obtenho aprovação para ingressar no curso de Graduação em Enfermagem da Unochapecó. Em 2007, inicio a graduação - no ano em que o curso se desafiava a desenvolver uma nova proposta curricular, cujo processo foi intensificado pela aprovação de um projeto junto ao Pró-Saúde, como citado acima. Dessa forma, a primeira turma a ingressar no curso de Graduação em Enfermagem com a nova proposta curricular foi minha, no ano de 2007 , tendo egressos no primeiro semestre de 2011.

A nova organização curricular do curso de Enfermagem propunha integrar, metodologicamente, áreas de conhecimento em núcleos. Esse foi o primeiro desafio que gerou em mim angústia, pois durante todo o ensino fundamental e médio, na escola formal, estudei por disciplinas, não tendo vivenciado outra forma de aprender a não ser de modo fragmentado. A organização por núcleos nos fazia estudar diversos conteúdos interligados. No início isso gerou dificuldade pela quantidade de conteúdos, mas posteriormente eles fizeram sentido e facilitavam o processo ensinoaprendizagem. Hoje, a partir dessas experiências que o curso proporcionou, visualizo que a integração de conteúdos favorece a aprendizagem.

Os conteúdos interligados me possibilitaram perceber o mundo como uma complexa rede de relações, na qual todo e qualquer micro-movimento reverbera, com consequências sobre essa rede. A partir disso, compreendese que é necessário encontrar e sugerir respostas criativas e resolutivas, que transformam a realidade, o que requer superar a concepção da saúde como fenômeno afeto à cura apenas no sentido biológico, reconhecendo-a como processo e produto integrado a uma rede de interações biopsicossociais.

Para Larrosa Bondía (2002), as experiências favorecem respostas criativas de enfrentamento, capazes de transformar a realidade. Nisso consiste também o saber da experiência, adquirido no modo como as pessoas respondem ao que vai acontecendo ao longo da vida e no sentido que se dá a esses acontecimentos.

Durante toda a graduação realizamos diversas atividades integradas aos projetos do Pró-Saúde. Já no primeiro semestre, vivenciamos uma visita ao antigo lixão, ao aterro sanitário do município e à terra indígena Toldo Chimbangue. As visitas me possibilitaram desconstruir a imagem do enfermeiro que atua somente no hospital e visualizar o enfermeiro em 
diversos cenários de prática, além de introduzir uma nova concepção de saúde e ambiente, a partir do conceito de promoção de saúde.

Reconhecer que saúde e doença são dimensões de um processo em que as pessoas são protagonistas requer reconhecer que isso está intimamente relacionado às condições subjetivas e objetivas da existência. Para tanto, a compreensão sobre saúde deve ultrapassar os limites teóricos e conceituais e partir da reflexão da realidade para que tenha impacto direto na vida das pessoas, promovendo transformação (SÁ; FERRETTI; KLEBA, 2013).

As visitas me fizeram refletir e compreender que somos seres em interação e que o conhecimento nasce das interações dialógicas entre os homens. O profissional da saúde possui um conhecimento, o do campo científico, e não pode considerá-lo único, em detrimento de outros saberes. O reconhecimento de outros saberes - tradicionais, populares, religiosos, entre outros - como saberes válidos nos faz compartilhar a diversidade e, por meio do diálogo, construir novos saberes viáveis.

Realizamos também uma viagem à cidade de Porto Alegre-RS (450 quilômetros distante de Chapecó), onde visitamos o Museu de Ciência e Tecnologia da Pontifícia Universidade Católica. A viagem me possibilitou ampliar os conhecimentos culturais, perceber novas formas de ensino-aprendizagem e também a existência de aprendizado para além da sala de aula.

Essas atividades possibilitaram visualizar o papel do professor fora da sala de aula. A experiência proporcionou aprender o significado das metodologias ativas, do desenvolvimento da autonomia, causando grande admiração pela forma como os docentes, cuidadosamente, possibilitaram essas experiências. A vivência possibilitou experienciar o que Freire nos diz: "[...] ensinar não é transferir conhecimento, mas criar as possibilidades para a sua própria produção ou a sua construção". (FREIRE, 2016, p. 47).

Além disso, fizemos uma viagem de estudos para São Miguel das Missões, município situado na região oeste do Rio Grande do Sul, em que pudemos desenvolver sentidos, como sensibilidade, audição e capacidade de observação de detalhes, imprescindíveis para o trabalho em enfermagem; além de aprender sobre história, cultura e arte.

A necessidade de conhecer aspectos históricos e culturais da vida de indivíduos e coletividades foi adquirindo sentido nessas experiências, fazendome perceber as amarras às quais somos submetidos em nossa formação de valores no cotidiano. Conhecer o paciente como protagonista, mas também sua condição de sujeito inserido em um contexto histórico de vida, que determina certos limites em seu desenvolvimento pleno como ser humano, possibilitoume compreender melhor seu mundo e desenvolver empatia no processo de 
cuidado. Essa experiência despertou em mim maior abertura e contribuiu em minha formação de como ser enfermeira crítica e sensível.

As relações que estabelecemos com a realidade são relações de pluralidade, criticidade e temporalidade. Se o homem não fosse crítico, seria apenas um ser acomodado, adaptado à realidade-ambiente, sendo que nem história e nem cultura fariam sentido, não teriam liberdade. E é porque não se acomoda, que o homem cria, recria, decide e transforma (FREIRE, 1979).

Outra atividade que realizei durante a graduação foi o projeto Vivências Interdisciplinares e Multiprofissionais (VIM), que reuniu estudantes de diversos cursos da área da saúde em grupos que, mediados por um tutor, debatiam e realizavam experiências de reconhecimento sobre desafios e avanços na construção do SUS em territórios da atenção básica no município. O VIM me possibilitou experienciar a interdisciplinariedade na troca de experiências entre os acadêmicos, no trabalho em equipe multiprofissional e na integração ensino-serviço. Com isso, foi possível ter a experiência de lidar com conflitos, de negociar e buscar consensos, na perspectiva do interesse coletivo, sem desconsiderar singularidades.

O exercício da aprendizagem coletiva, e do aprender com o outro nem sempre é tarefa fácil. Na medida em que o trabalho em enfermagem deve ser realizado em equipe, o diálogo é ferramenta imprescindível no cotidiano profissional. Foi por meio de atividades como o VIM que fortaleci habilidades de comunicação e liderança. Ao inspirar-me em Freire (2015), considero o diálogo como um processo que inclui a fala e a escuta, com humildade, em busca da revelação da palavra e da transformação da ação.

Estar aberto aos outros significa estar com disponibilidade curiosa à vida. A abertura viabiliza o diálogo do ser inacabado. Só é inacabado porque se abre ao mundo e aos outros à procura de explicações e de respostas para as perguntas. $O$ sujeito que se abre aos outros estabelece relação dialógica, que é confirmada pela curiosidade (FREIRE, 2016).

O mapeamento do território adstrito à unidade de saúde, com suas fragilidades e potencialidades, foi outra atividade que realizamos no curso. A atividade me despertou o gosto pelo trabalho na saúde coletiva, pela possibilidade de maior aproximação com as pessoas e com a comunidade, em seu contexto de vida, de conhecer e compartilhar suas histórias por meio do diálogo amoroso e engajado. E também por poder vivenciar diretamente que saúde e doença são dois polos de um mesmo processo, permeado por determinantes e condicionantes sociais, que sofre interferências políticas, econômicas e culturais, sendo que, nesse complexo emaranhado de fatores, o enfermeiro pode contribuir significativamente, principalmente no 
desenvolvimento da autonomia dos sujeitos. Como não tinha muita afinidade em relação às demandas próprias do ambiente hospitalar, desse período em diante escolhi como campo de trabalho a atenção básica, preferencialmente no âmbito da Estratégia Saúde da Família.

O ser humano é sujeito quando reflete criticamente sobre sua realidade e seu ambiente concreto. Quanto mais emergir na realidade, no ambiente concreto, mais perto estará de estar pronto para intervir na realidade a fim de modificá-la. Essa educação que desenvolve a consciência e a crítica, em que ele escolhe e decide, liberta-o (FREIRE, 2015)

Outra atividade que merece destaque foi o Planejamento Estratégico Situacional (PES), que realizamos no estágio de Gestão e Gerência em Serviços de Saúde. O PES é uma ferramenta de gestão e gerência em saúde e enfermagem que viabiliza coerência com os princípios do SUS, e que me possibilitou visualizar como a gestão dos serviços de saúde pode ser realizada de forma participativa e de acordo com a realidade local, de forma dialógica. Essa atividade me proporcionou desenvolver a capacidade de dialogicidade, compartilhando diferentes saberes e fomentando a participação da comunidade como provedora da autonomia dos sujeitos, em busca do crescimento mútuo e do saber mais.

A partir do diálogo, podemos pronunciar o mundo segundo nosso modo de ver. Isso implica uma práxis social e é o compromisso entre o que se diz e o que se faz. A possibilidade do diálogo abre caminhos para pensar a vida em sociedade, pensar sobre cultura, educação a linguagem, e para transformar o mundo. O desafio que Freire nos provoca significa construir novos saberes a partir do diálogo que promove a partilha de mundos diferentes (ZITKOSKI, 2016a).

Durante a graduação diversos desafios emergiram, em função da nova proposta curricular. Realizamos alguns enfrentamentos como estudantes pelas dificuldades em nos adaptar à nova proposta curricular. Alguns estudantes reclamavam das avaliações acumulativas e outros tinham em mente que o aprendizado deveria ser baseado nas técnicas, não considerando as atividades diferenciadas como momentos de aprendizado, situação que gerou conflitos em vários momentos.

Os enfrentamentos eram sempre mediados pelo diálogo entre o corpo docente e discente. Buscávamos conversar com os professores e com a coordenação de curso de forma organizada e articulada. Reconheço que algumas vezes tive papel importante nesse diálogo, como liderança da turma, e atribuo essa potencialidade às minhas experiências de participação na juventude. Por mais nova e desafiadora que fosse a proposta pedagógica 
do curso, sempre acreditei muito nela, pela potencialidade de transformação que propunha.

A proposta do aprender fazendo nos colocava, estudantes e professores, como sujeitos protagonistas do processo ensino-aprendizagem, possibilitando a criticidade e a criatividade por parte dos envolvidos. Reconheço que as atividades que experienciei desenvolveram em mim a sensibilidade e o desejo de trabalhar como docente com metodologias participativas e problematizadoras.

O diálogo proposto por Paulo Freire consiste na comunicação que propõe a reflexão. Esse processo não deve ser confundido com a aceitação de tudo que a outra parte do diálogo pronuncia, mas de ouvir e falar de forma comprometida com a busca pela verdade (FREIRE, 2015).

Da mesma forma, notamos que a proposta também era um desafio para os professores. Nos momentos de diálogo, os docentes sempre foram sinceros em dizer que a metodologia era inovadora e que também estavam em constante aprendizado durante o processo. Dessa forma a educação permanente se fazia presente, pois todos éramos, professores e estudantes, sujeitos do processo ensino-aprendizado, de forma dialógica, discutindo, ressignificando e aprendendo constantemente em nossa prática cotidiana. Isso reflete em meu processo de construção como docente, com a certeza de que o conhecimento não está acabado e que estamos em permanente busca por ele, de forma dialógica na díade estudante-docente, mediatizados pelo mundo.

Na proposta de educação problematizadora de Freire, os educandos são chamados a conhecer, sendo que os educadores assumem o papel de mediadores da reflexão crítica, que ambos vivenciam de forma dialógica. Assim, a função do educador é a problematização e os educandos tornamse investigadores críticos em diálogo com o orientador, que também é investigador (FREIRE, 2015).

Nesse sentido, o conhecimento não deve ser transferido do professor para o estudante, mas deve ser testemunhado e vivido e isso só pode ser proporcionado por caminhos democráticos e não autoritários (FREIRE, 2016). Os sujeitos devem ser protagonistas na busca pelo conhecimento, inquietos e em permanente processo educativo. Esse processo exige humildade, que é a luta pelo respeito, pela defesa dos direitos e da dignidade. Isso garante a convivência com as diferenças, sem excluir o debate e o diálogo sobre elas (REDIN, 2016).

Como forma de aproveitar todos os espaços de formação, durante a graduação tive a oportunidade de ser bolsista do PET-Saúde, o que me possibilitou experienciar a integração ensino-serviço e o trabalho 
multiprofissional em saúde, além de o contato com a pesquisa científica, os sistemas de informação em saúde e a interdisciplinariedade.

Essas vivências proporcionaram perceber que a formação não acontece apenas em sala de aula, ou ainda nos laboratórios, mas se realiza nos diversos espaços da instituição de ensino e fora dela. Elas possibilitaram, também, visualizar a importância da articulação entre o ensino, a pesquisa e a extensão para a formação; e conhecer com profundidade o Sistema Único de Saúde, entendendo-o como patrimônio da sociedade brasileira, conquistado por meio da participação social, garantindo o direito à saúde da população. Isso fez com que me tornasse - pessoal e profissionalmente - militante do SUS, engajada na luta por sua consolidação, enfatizando novamente o papel político da formação no curso e também do ser professor (PRADO; REIBNITZ, 2016).

$\mathrm{Na}$ medida em que o ser humano reflete sobre seu contexto de vida, respondendo aos desafios que a ele se apresentam, e as relações que estabelece com o mundo, criando e recriando realidades, ele dinamiza e cria cultura. "Cultura é todo resultado da atividade humana, do esforço criador e re-criador do homem, de seu trabalho por transformar e estabelecer relações de diálogo com outros homens" e com o mundo (FREIRE, 1980, p. 38).

Dessa forma, o ser humano, sendo sujeito e criando cultura, faz história quando sugere novas formulações, mudanças na maneira de atuar, nas atitudes e nos comportamentos. Portanto, "[...] é preciso que a educação, [...] esteja adaptada ao fim [...] permitindo ao homem chegar a ser sujeito, construir-se como pessoa, transformar o mundo, estabelecer com os outros homens relações de reciprocidade, fazer a cultura e a história". (FREIRE, 1980, p. 39).

Em relação à prática profissional, sempre tive afinidade pela atenção básica. As vivências nos cenários de prática, durante a graduação, fortaleceram esse interesse e também a vontade de ingressar na carreira acadêmica. Durante os três anos atuando como enfermeira em uma equipe da Estratégia Saúde da Família em um município de pequeno porte no Oeste catarinense, inúmeras experiências foram somadas e desafios enfrentados. Esse momento deve ser considerado enriquecedor e teve contribuições para minha formação como profissional do SUS. Durante esse período, como enfermeira, foram desenvolvidas ações com base na integralidade, buscando o diálogo, em todas as situações de enfrentamento, para mediar conflitos. A tarefa de liderar equipe e a tomada de decisões não são fáceis e exigiram comprometimento com o diálogo a fim de que eu não me tornasse uma líder autoritária. Isso exige ação, reflexão e maturidade para aprender a lidar com os erros, ressignificando as práticas. 
Quando a ação é enfatizada ou exclusiva, converte-se o fazer em ativismo. A ação pela ação, quando minimiza a reflexão, nega a práxis verdadeira e isso gera uma ação antidialógica, impedindo que as ações sejam transformadas, enaltecendo a formação técnica, que impede os profissionais de questionarem e refletirem sobre seu agir. Por outro lado, a ação dialógica permite que os homens se reconheçam na ação-reflexão-ação, gerando uma teoria de ação transformadora, sendo que somente assim podem transformar o mundo (FREIRE, 2015).

Durante o período em que atuei na atenção básica, realizei uma especialização em Saúde Coletiva com ênfase em Estratégia Saúde da Família, modalidade magistério superior, em outra instituição de ensino da região. A escolha pela especialização se deu pela amorosidade pela área e também por ser meu campo de trabalho. Esse período me possibilitou contato com outros profissionais da saúde da região e o compartilhamento das experiências sobre as diversas realidades e nuances dos serviços de saúde presentes em nossa região.

Além disso, como a especialização era modalidade magistério superior, realizamos ao final uma prática docente voltada a estudantes de Graduação em Enfermagem. A atividade exigiu o preparo da aula e proporcionou, pela primeira vez, experienciar a docência. Durante as aulas utilizei diversas técnicas pedagógicas, baseadas em metodologias ativas de ensino-aprendizagem e também em momentos de aula expositivadialogada, vivenciadas por mim durante a graduação. A experiência teve grande aceitação por parte dos discentes, fato que, somado às experiências de minha formação e enquanto enfermeira, reviveu em mim o antigo sonho de ser professora.

A partir disso, decidi ingressar no mestrado em Ciências da Saúde da Unochapecó. De volta à academia, sabia que minha trajetória acadêmica e profissional teve, além das influências de meu contexto de vida, influências profundas do curso de Graduação em Enfermagem, fortalecidas pelas atividades desenvolvidas no Pró-Saúde e PET-Saúde. O retorno para o espaço de minha formação foi movido também pelo interesse em conhecer se e em que medida o Programa também influenciou a prática profissional de meus colegas enfermeiros. Assim, a temática da minha pesquisa de dissertação de mestrado refere-se às repercussões do Pró-Saúde na prática de enfermeiros egressos da Unochapecó (MATTIA, 2016).

O sujeito é fruto de um caminho de aprendizagens complexas que é determinado pelo movimento humano e de suas relações com outros sujeitos (PITANO, 2016). O sujeito da experiência é um sujeito que está exposto. 
Nessa situação, o importante não é a oposição e nem a imposição, mas sim, a exposição. É incapaz da experiência o sujeito que se impõe, ou se propõe, mas não se expõe (LARROSA BONDÍA, 2002)

A linha de pesquisa à qual estou vinculada no mestrado éTrabalho e Formação e Saúde, que estuda processos formativos e processos de trabalho dos profissionais da saúde. Durante o mestrado, atividades como prática de docência me aproximaram do ser docente, experiência que possibilitou vivenciar o mundo do trabalho docente. Durante o planejamento e o desenvolvimento das atividades, buscava a utilização de metodologias ativas e problematizadoras, que auxiliam o desenvolvimento da autonomia dos estudantes.

Também tive a oportunidade de participar novamente do projeto VIM, do qual havia participado como estudante, agora como tutora. A troca de papéis possibilitou vivenciar o que Paulo Freire traz em sua proposta de educação, pois enquanto discente o aprendizado no projeto foi intenso. $E$, agora, enquanto docente, foi novamente enriquecedor e me fez descobrir que continuamos sendo sujeitos dialógicos do processo ensino-aprendizagem.

Durante o mestrado fui apresentada por minhas orientadoras a Paulo Freire. A partir de então, desenvolvi um doce prazer pela leitura de suas obras. Além disso, cursei disciplinas que me aproximaram de suas ideias no Programa de Pós-Graduação em Ciências da Saúde, quais sejam: Ensino e Inovação em Saúde; Políticas e Práticas de Ensino na Saúde; e em uma disciplina no Programa de Pós-Graduação em Educação: Concepção Freireana na Educação Escolar, a qual me permitiu desvelar e enxergar as palavras do autor com outros olhares. Momento esse desafiador, afinal, sair da zona de conforto e caminhar pelas trilhas da interdisciplinariedade, descobri no caminho, é um exercício árduo. Porém, esse é o caminho que me aproxima de meu antigo sonho de ser professora e possibilita que eu compreenda a formação do ser docente como processo permanente de educação, no qual assumo protagonismo, mas também fortaleço relações dialógicas com outros docentes em formação.

Nas obras de Paulo Freire descobri que ninguém lê e permanece como no início. Quem lê suas obras certamente passa por profundas transformações. É preciso, ainda, transformar suas palavras em atitudes concretas, por meio da práxis, pois, como ele mesmo diz, a palavra sem ação é verbalismo, e a ação sem reflexão é ativismo (FREIRE, 2015). 


\section{CONSIDERAÇÕES FINAIS}

Escrever essa narrativa me possibilitou relembrar minha trajetória acadêmica e reconhecer os reflexos que ela teve em minha prática profissional e em minha construção docente, bem como, reaprender, ressignificar conceitos e aproximá-los de minha práxis.

A experiência da formação teve influências relevantes nas escolhas e caminhos percorridos no meio acadêmico, na prática profissional e na docência. Por isso, tomamos por conceito de experiência o que Larrosa Bondía (2002, p. 21) traz:"A experiência é o que nos passa, o que nos acontece, o que nos toca. Não o que se passa, não o que acontece ou o que toca".

O Pró-Saúde, por meio das iniciativas do curso de Enfermagem da Unochapecó, gerou oportunidades de aprendizado, de envolvimento e maior comprometimento com a construção do SUS, bem como de protagonismo, como sujeito do processo permanente de formação profissional e docente. Destaco como experiências referências as visitas em diferentes cenários, que me fizeram reconhecer oportunidades de aprendizagem para além da sala de aula; o projeto VIM, que desvelou a importância do trabalho em equipe, multiprofissional, no processo de cuidado em saúde; e as metodologias ativas, como estratégia de formação do protagonismo, fortalecendo a autonomia, mas também a dialogicidade.

O trajeto percorrido durante o mestrado me permitiu perceber que a formação possui implicações na prática profissional, na docência e também nos modos de ver e me relacionar com o mundo. Descobri que, como eu, muitos outros são militantes, e estão engajados na consolidação do Sistema Único de Saúde e, por isso, não estou sozinha.

Lendo Paulo Freire, reconheço que venho buscando incorporar seus ensinamentos como prática profissional e de vida. E é assim que reconheço que encerro mais essa etapa, de conclusão do mestrado em Ciências da Saúde, profundamente transformada. Espero que essa transformação possa também transformar minhas práticas e atitudes diárias, bem como transformar o ambiente em que vivo e trabalho cotidianamente, assim como contribuir na transformação das pessoas que convivem comigo. $\mathrm{E}$, humildemente, mas cheia de esperança e confiança, contribuir para a comunidade acadêmica, trabalhadores, estudantes e com todos que, assim como eu, acreditam no SUS. 
I, NURSING STUDENT AND NURSE: AN AUTOBIOGRAPHICAL NARRATIVE ON TRAINING, PRACTICE AND TEACHING IN THE FREIRIAN PERSPECTIVE

ABSTRACT:The following article aims to describe, through the autobiographical narrative, how the choices made throughout my personal and professional trajectory built me as a nursing teaching. The Nursing course of Unochapecó was developed within the scope of Pro-Health, which has its starting point in Paulo Freire and its scope of application in the development of the subjects' autonomy in the teaching-learning process as theoretical-methodological references. The training experience, based on Freire's pedagogical praxis, had direct influence on choices, attitudes and paths covered in my professional practice and academic environment, creating learning opportunities and commitment, and transforming the world and people around me in the process.

KEYWORDS: Autobiographical Narrative. Nursing Training. Professional Practice. Teaching.

YO, ESTUDIANTE DE ENFERMERÍA Y ENFERMERA:UNA NARRATIVA AUTOBIOGRÁFICA SOBRE FORMACIÓN, PRÁCTICA PROFESIONAL Y ENSEÑANZA EN LA PERSPECTIVA FREIRIANA

RESUMEN: A través del método de narrativa autobiográfica, este artículo busca describir de qué forma las decisiones tomadas durante mi trayectoria personal y profesional ejercen influencia en la construcción de ser una enfermera docente. La formación en el Curso de Enfermaría de la Unochapecó fue basada en los ejes del Pró-Saúde, que se fundamenta en las teorías del pensamiento de Paulo Freire, utilizando principalmente cuestiones concernientes a la problematización y al desarrollo de la autonomía de sujetos en proceso de enseñanza-aprendizaje, como referencias teórico-metodológicas. La experiencia de la formación, basada en la praxis pedagógica freiriana, ejerció influencia directa en las decisiones, actitudes y caminos recorridos en la práctica profesional y en el medio académico, generando oportunidades de aprendizaje y compromiso en la transformación del mundo y de las personas que conviven conmigo, como resultado de ese proceso formativo.

Palabras Clave: Narrativa. Formación en Enfermaría. Práctica Profesional. Enseñanza.

\section{REFERÊNCIAS}

BAQUERO, R. Educação de adultos. In: STRECK, D. R.; REDIN, E.; ZITKOSKI, J.J. Dicionário Paulo Freire. 3 ed. Belo Horizonte: Autentica Editora, 2016. p. 136-137.

BRASIL. Ministério da Saúde. Secretaria de Gestão do Trabalho e da Educação na Saúde. Programa Nacional de Reorientação da Formação Profissional em Saúde - Pró- 
-Saúde: objetivos, implementação e desenvolvimento potencial. Brasília: Ministério da Saúde, 2007. p. 87.

BRASIL. Resolução CNE/CES n. 3 de 7 de novembro de 2001. Institui Diretrizes Curriculares Nacionais do Curso de Graduação em Enfermagem. Conselho Nacional de Educação. Diário Oficial da União, Ministério da Educação, Brasília, DF, nov. 2001. Seção 1, p. 37

FABRE, M. Fazer de sua vida uma obra. Educação em Revista, Belo Horizonte, v.27, p.347-368, abr. 2011.

FREIRE, P. Pedagogia da autonomia: saberes necessários à prática educativa. 53 ed. São Paulo: Paz e Terra, 2016.

. Pedagogia do oprimido. 59. ed. Rio de Janeiro: Paz e Terra, 2015.

. A educação na cidade. 7 ed. São Paulo: Cortez, 2006.

. Conscientização: teoria e prática da libertação. 3 ed. São Paulo: Moraes, 1980.

. Educação e mudança. 12 ed. Rio de Janeiro: Paz e Terra, 1979.

GASTAL, M. L. A.; AVANZI, M. R. Saber da experiência e narrativas autobiográficas na formação inicial de professores de biologia. Ciência \& Educação, Bauru, v. 21, n. 1, p. 149-158, 2015.

LARROSA BONDÍA, J. Notas sobre a experiência e o saber da experiência. Revista Brasileira de Educação, Campinas, n.19, p. 20-28, jan/abr. 2002.

MATTIA, B. J. Programa Nacional de Reorientação da Formação Profissional em Saúde: repercussões na prática de enfermeiros. 2016. 244 f. Dissertação (Mestrado em Ciências da Saúde) - Universidade Comunitária da Região de Chapecó, Chapecó, 2016.

PASSEGGI, M. C.; SOUZA, E. C.; VICENTINI, P. P. Entre a vida e a formação: pesquisa (auto)biográfica, docência e profissionalização. Educação em Revista, Belo Horizonte, v.27, p.369-386, abr. 2011

PITANO, S. Sujeito Social. In: STRECK, D. R.; REDIN, E.; ZITKOSKI, J.J. Dicionário Paulo Freire. 3 ed. Belo Horizonte: Autentica Editora, 2016. p. 384-385.

PRADO, M. L.; REIBNITZ, K. S. (Org.). Paulo Freire: a boniteza de ensinar e aprender na saúde. Florianópolis: NFR/UFSC, 2016.

REDIN, E. Humildade. In: STRECK, D. R.; REDIN, E.; ZITKOSKI, J.J. Dicionário Paulo Freire. 3. ed. Belo Horizonte: Autentica Editora, 2016. p. 212-213.

ROMÃO, J. E.; et al. Círculo epistemológico: círculo de cultura como metodologia de pesquisa. Educação e Linguagem, São Bernardo do Campo, n. 13, p. 173-195, jan./ jun., 2006.

ROMÃO, J. E. Educação. In: STRECK, D. R.; REDIN, E.; ZITKOSKI, J.J. Dicionário Paulo Freire. 3 ed. Belo Horizonte: Autentica Editora, 2016. p. 212-213. 
SÁ, C.; FERRETTI, F.; KLEBA, M. E. Concepções contemporâneas sobre saúde. In: SÁ, C.; FERRETTI, F.; BUSATO, M. A. (Org.). Ensaios contemporâneos em saúde: uma perspectiva interdisciplinar. Chapecó: Argos, 2013. p. 33-45.

SCHOMMER, P.C.; BOULLOSA, R. F. Com quantas andorinhas se faz um verão? Práticas, relações e fronteiras de aprendizagem. In: SCHOMMER, P. C; SANTOS, Í. G. Aprender se aprende aprendendo: construção de saberes na relação entre universidade e sociedade. Salvador: CIAGS/UFBA, 2010. p. 17-42.

ZITKOSKI, J. J. Diálogo/Dialogicidade. In: STRECK, D. R.; REDIN, E.; ZITKOSKI, J.J. Dicionário Paulo Freire. 3. ed. Belo Horizonte: Autentica Editora, 2016a. p. 117-118.

ZITKOSKI, J. J. Humanização/Desumanização. In: STRECK, D. R.; REDIN, E.; ZITKOSKI, J.J. Dicionário Paulo Freire. 3 ed. Belo Horizonte: Autentica Editora, 2016b. p. 210-211.

Bianca Joana Mattia: Enfermeira. Estudante do mestrado do Programa de Pós-Graduação "Stricto Sensu" em Ciências da Saúde (PPGCS) da Universidade Comunitária da Região de Chapecó - Unochapecó. Membro do Grupo de Pesquisa Formação e Trabalho em Saúde do PPGCS.

E-mail: biancajm@unochapeco.edu.br

Maria Elisabeth Kleba: Doutorado em Filosofia pela Universitat Bremen (2000), convalidado pelo Programa de Pós Graduação em Enfermagem da Universidade Federal de Santa Catarina - UFSC. Professora da Área de Ciências da Saúde e dos mestrados em Políticas Sociais e Dinâmicas Regionais e em Ciências da Saúde (PPGCS) da Universidade Comunitária da Região de Chapecó - Unochapecó. Coordena o Grupo de Pesquisa em Políticas Públicas e Participação Social. Membro do Grupo de Pesquisa Formação e Trabalho em Saúde do PPGCS.

E-mail: Ikleba@unochapeco.edu.br

IVo DickMAnN: Mestre e doutor em Educação (UFPR). Professor titular do PPGE - mestrado em Educação da Universidade Comunitária da Região de Chapecó - Unochapecó. Líder do Grupo de Estudos, Pesquisa e Documentação em Educação Ambiental Freireana - PALAVRAÇÃO.

E-mail: educador.ivo@unochapeco.edu.br 